\title{
Linking soil's volatilome to microbes and plant roots highlights the importance of microbes as emitters of belowground volatile signals
}

\author{
Denis Schenkel, ${ }^{1,2}$ Aurélie Deveau, ${ }^{3}$ Jun Niimi, ${ }^{1}$ \\ Pierre Mariotte, ${ }^{4,5}$ Amarante Vitra, ${ }^{4,5}$ Marco Meisser, ${ }^{6}$ \\ Alexandre Buttler ${ }^{4,5,7}$ and Richard Splivallo $\mathbb{1 D}^{1,2,4^{*}}$ \\ ${ }^{1}$ Institute for Molecular Biosciences, Goethe University \\ Frankfurt, Max-von-Laue Str. 9, 60438, Frankfurt am \\ Main, Germany. \\ ${ }^{2}$ Integrative Fungal Research Cluster, 60325, Frankfurt, \\ Germany. \\ ${ }^{3}$ Institut national de la recherche agronomique (INRA), \\ Unité Mixte de Recherche 1136 INRA-Université de \\ Lorraine, Interactions Arbres/Microorganismes, Centre \\ INRA-Grand Est-Nancy, 54280, Champenoux, France. \\ ${ }^{4}$ Laboratory of Ecological Systems (ECOS), Station 2, \\ École Polytechnique Fédérale de Lausanne (EPFL), \\ School of Architecture, Civil and Environmental \\ Engineering (ENAC), 1015, Lausanne, Switzerland. \\ ${ }^{5}$ Swiss Federal Institute for Forest, Snow and \\ Landscape Research (WSL), Site Lausanne, Case \\ postale 96, 1015, Lausanne, Switzerland. \\ ${ }^{6}$ Agroscope, Route de Duillier 50, Case Postale 1012, \\ 1260, Nyon, Switzerland. \\ ${ }^{7}$ Laboratoire de Chrono-Environnement, UMR CNRS \\ 6249, UFR des Sciences et Techniques, 16 route de \\ Gray, Université de Franche-Comté, F-25030, \\ Besançon, France.
}

\section{Summary}

Plants and microbes release a plethora of volatiles that act as signals in plant-microbe interactions. Characterizing soil's volatilome and microbiome might shed light on the nature of relevant volatile signals and on their emitters. This hypothesis was tested by characterizing plant cover, soil's volatilome, nutrient content and microbiomes in three grasslands of the Swiss Jura Mountains. The fingerprints of soil's volatiles were generated by solid-phase micro-extraction gas chromatography/mass spectrometry, whereas high-throughput sequencing

Received 6 February, 2019; revised 13 March, 2019; accepted 19

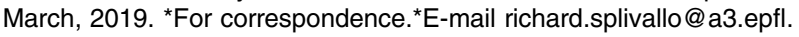
ch; Tel. (+49) 69798 42193; Fax (+49) 6979829527. was used to create a snapshot of soil's microbial communities. A high similarity was observed in plant communities of two out of three sites, which was mirrored by the soil's volatilome. Multiple factor analysis evidenced a strong association among soil's volatilome, plant and microbial communities. The proportion of volatiles correlated to single bacterial and fungal taxa was higher than for plants. This suggests that those organisms might be major contributors to the volatilome of grassland soils. These findings illustrate that key volatiles in grassland soils might be emitted by a handful of organisms that include specific plants and microbes. Further work will be needed to unravel the structure of belowground volatiles and understand their implications for plant health and development.

\section{Introduction}

Vascular plants, with more than 300000 species (Christenhusz and Byng, 2016), occupy a wide range of habitats spanning from deserts to rainforests. Adaptation of plants to varying environmental conditions is oftentimes facilitated through belowground interactions with microbes, which might improve plant fitness and resistance to stress, as well as shape the coexistence pattern between species (Hacquard et al. 2015; 2017).

Microbes surrounding plant roots are predominantly composed of bacteria and fungi (Mendes et al. 2013). At the plant root level, $80 \%-90 \%$ of terrestrial plants are associated with mycorrhizal fungi (Smith and Read, 2008; Bonfante and Genre, 2010). These beneficial microbes simultaneously colonize roots and soil, thereby increasing plants nutrient uptake (Farzaneh et al., 2011) and resistance to drought (Mariotte et al., 2013; 2017) and pests (El Komy et al., 2015; Frąc et al., 2018). Root colonization by these symbionts is highly dynamic and competitive as more than 100 symbiotic fungal species might simultaneously co-exist on the roots of a single plant (Bahram et al., 2011; Deveau, 2016). Besides mycorrhizal fungi, plant roots also contain non-mycorrhizal fungal endophytes, endosymbiotic microbes living within plant tissues (Rodriguez et al., 2009; Kia et al., 2017). Depending on plant-fungal species combination, these endophytes can 
influence plant development in different ways, ranging from growth inhibition to growth promotion (Kia et al., 2017). For instance, endophytic Fusarium species have been shown to inhibit plant development and Helotiales strains to enhance it (Almario et al., 2017; Kia et al., 2017). Finally, roots are also prone to attacks by pathogenic fungi (i.e. Fusarium and Verticillium) and oomycetes (i.e. Pythium and Phytophthora) dwelling in soil, which might cause wilts, blights and rots in host plants (Parry et al., 1995; McCormick et al., 2011). Overall, these examples highlight the importance of root colonizing fungi in plant health and development.

Bacteria are another important component of the plant root microbiome that plays a key role in plant nutrition, root development and plant health. Some bacterial strains enhance nutrient acquisition in plants (Nissinen et al., 2012; Bulgarelli et al., 2013; Vandenkoornhuyse et al., 2015; Kielak et al., 2016), support stress adaptation (Vandenkoornhuyse et al., 2015) or, like Bacillus amyloliquefaciens, suppress plant pathogens (Santhanam et al., 2015; Gómez Expósito et al., 2017; Saechow et al., 2018). Others can have deleterious or no visible effects on plants (Mansfield et al., 2012). Bacterial diversity has been shown to decrease from the bulk soil to the rhizosphere, the thin layer of soil in direct contact with roots, and from the rhizosphere to the endosphere that makes up the inner root space (Turner et al., 2013; Mendes et al., 2014; Edwards et al., 2015; Zgadzaj et al., 2016). Members of the Proteobacteria, Actinobacteria and Bacteroidetes bacterial phyla are mostly represented in the rhizosphere and endosphere of numerous plant species (Ofek-Lalzar et al., 2014; Schlaeppi et al., 2014). Some studies performed under controlled greenhouse conditions have demonstrated a relative stability in root associated bacterial communities; however, dynamic bacterial communities that react to changing environmental factors are surely more common under natural conditions (Edwards et al., 2015; Marupakula et al., 2016).

Belowground plant-microbe interactions are in part regulated by chemical signals secreted by one organism that induces changes in the other. These signals might be watersoluble proteins or small molecules (Martin and Kamoun, 2011). For instance, soil microbes release phytohormones (i.e. auxins and gibberellins) that might modulate plant growth and immunity (reviewed in the study by PerselloCartieaux et al., 2003). Plants are also able to shape their root microbiome through root exudates, a broad range of water-soluble metabolites [i.e. amino and organic acids, sugars, peptides; reviewed in the study by van Dam and Bouwmeester (2016)]. Exudates are, however, not the only signals encountered in plant-microbe interactions. Volatile organic compounds, small molecules with a low boiling point and high vapour pressure, are indeed another important group of chemical signals exchanged between plants and microbes. Because of their volatile nature, volatile organic compounds can diffuse in the soil and convey messages many centimetres away from their emitters (Rasmann et al., 2005; Wenke et al., 2010; Peñuelas et al., 2014; Massalha et al., 2017; Schulz-Bohm et al., 2018; Sharifi and Ryu, 2018). To date, 841 volatiles that might act as signals to plants have been documented from soil associated microbes, even though a much higher number might exist (Schenkel et al., 2015). For instance, 2,3-butanediol released by Gram-positive Bacillus bacteria promote the growth of Arabidopsis plants (Ryu et al., 2003). Likewise, a mixture of 2-methyl-propanol, 3-methyl-butanol, methacrylic acid and isobutyl acetate produced by the fungal genus Phoma induce growth promotion in tobacco (Naznin et al., 2013). Plants are similarly able to attract bacteria from bulk soil by the release of volatiles through their roots as recently illustrated for the grass species Carex arenia (Schulz-Bohm et al., 2018). The latter examples highlight, however, that studies unravelling the role of specific signals generally focused on simplified laboratory setups, which are far from representing natural communities. Those communities are much more complex in terms of plant assemblages, root microbiomes and exchanged signals. Yet, studies of signals in complex communities have to date been hindered by technical challenges, as reflected by the scarce information available on biogenic volatiles in soil [reviewed in the study by Peñuelas et al. (2014)].

The aim of this study was to address the latter gap in knowledge. Specifically, the first goal was to investigate to which extent belowground microbial communities, soil's chemical properties and plant communities correlated to the soil's volatilome. The second aim was to identify specific emitters of relevant volatile signals. Three semi-natural grasslands, diverse plant communities mostly composed of grasses and forbs, were used here to address these questions. A comprehensive approach of metabolomics by gas chromatography/mass spectrometry (GC/MS) and highthroughput sequencing was employed to extensively characterize soil's volatilome as well as belowground fungal and bacterial communities. Multivariate statistics were then used to highlight any possible associations among soil's volatilome, soil nutrients, plants, bacteria and fungi.

\section{Results}

\section{Vegetation cover}

Vegetation of all three sites was dominated by grass species, ranging in abundance from roughly $75 \%$ in site 1 to slightly more than $50 \%$ in site 3 (Fig. 1A). Sites 1 and 2 were the most similar in terms of grass species, with the three dominant species Lolium perenne, Poa trivialis and Dactylis glomerata making up more than $75 \%$ of all grasses in both sites (Fig. 1B). By contrast, these two species were mostly absent in site 3 , where Agrostis capillaris and Festuca rubra made up more than 
$85 \%$ of all grass species. Forbs and legumes ranged second in abundance after grasses in all three sites. As for the pattern observed for grasses, sites 1 and 2 were the most similar in terms of forbs and legumes plant community composition (Fabaceae and Asteraceae), and differed the most from site 3 . A comparable pattern can be seen in terms of the number of plant species that are common or specific to the three sites (Table S1). Forage yields were $7.3( \pm 0.6)$ tons ha ${ }^{-1}$ (site 1$), 7.0( \pm 0.8)$ tons ha $^{-1}$ (site 2) and 4.6 ( \pm 0.6$)$ tons ha ${ }^{-1}$ (site 3 ) dry weight. Based on the Mann-Whitney statistical test, only the yield of site 3 was significantly lower than the one of the two other sites.

\section{Soil parameters}

Soil was characterized in the three sites in terms of nutritional properties. Microbial carbon, total nitrogen and microbial nitrogen were the highest in sites 2 and 3 (Fig. S1A, S1B, Mann-Whitney test, $p<0.05)$. Nitrate, soil inorganic nitrogen, soil phosphorus and microbial phosphorus were the highest in site 2. By contrast, ammonium was the highest in site 3 , which had the biggest proportion of forbs and legumes. Soil carbon was the only parameter that significantly increased from site 1 to 3 , according to the increasing altitude. Significant differences were also observed in nutrient ratios (Fig. S1C). For instance, microbial and soil C:P ratios were highest in site 3 , microbial $\mathrm{N}: \mathrm{P}$ ratios were lowest in site 1 and soil $N: P$ ratios lowest in site 2. Differences were furthermore observed in soil $\mathrm{pH}$ and mean annual temperatures (Table S2).

\section{A Plant families}

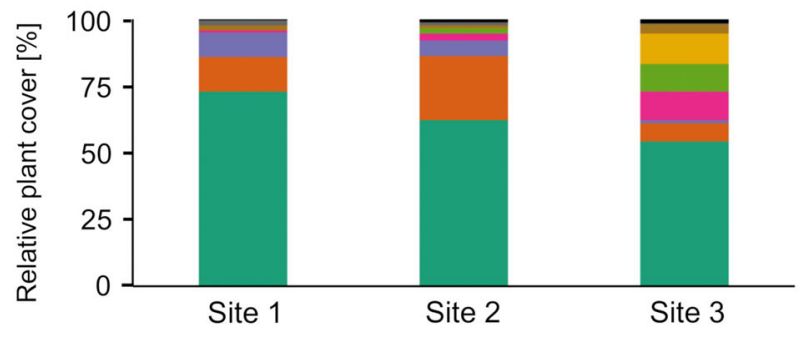

\section{B Grass species}

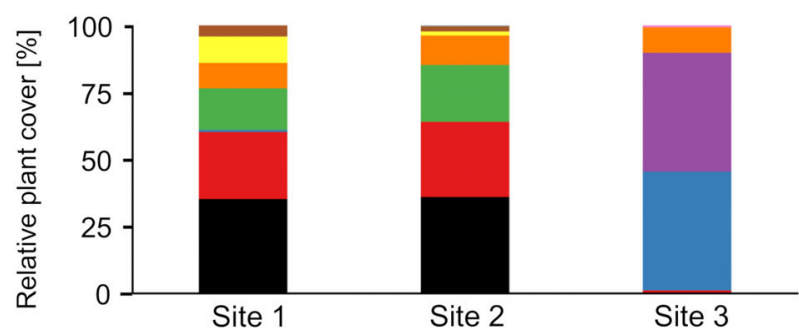

\section{Soil's volatilome}

Soil samples were further characterized in terms of volatilome for all three sites. Chromatograms were highly complex as illustrated in Fig. S2, hindering the structure identification of most volatiles. Raw GC/MS data are provided for a representative sample of each site (along with an alkane series) as supplemental material. Nevertheless, the goal here was not to definitely identify compounds but rather to compare the volatilome of the three sites, which can be done without full structure identification. To this end, fingerprints of volatile organic compounds were generated with the Tagfinder software that creates a matrix of TAGs, corresponding to specific mass fragments $(\mathrm{m} / \mathrm{z})$ within a retention time window (Luedemann et al., 2008). Processing the data of all sites and further filtering resulted in 298 TAGs. A heatmap illustrates those 298 TAGs (Fig. 2). Considering a TAG to be present in one site if present in at least one sampling plot (Fig. S6), 62\% of all TAGs were common to all three sites, while the proportion of TAGs shared between two sites ranged from six to $10 \%$, with site 1 and 2 having the highest proportion in common (Table S1). By contrast zero to $9 \%$ of the TAGs were site specific, and site 3 had the highest proportion of sitespecific TAGs (Table S1). Overall, similarly to what has been observed in plant cover, these results highlight more similarities in the volatile profiles of sites 1 and 2 and marked differences with site 3 .

\section{Soil's bacterial and fungal communities}

Microbial communities (fungi and bacteria) were further characterized from the soil of each plot. High throughput sequencing yielded on average ( \pm standard deviation)
Poaceae

Fabaceae

Asteraceae

Ranunculaceae

Polygonaceae

Rosaceae

Plantaginaceae

Caryophyllaceae

other
Fig. 1. Plant community composition in the three grassland sites.A. Relative proportion of botanical families of the eight most dominant plant families in the three study sites. B. Species distribution within the Poaceae family. Sites 1 and 2 were the most similar in terms of plant families and grass species.
Lolium perenne

Poa trivialis

Agrostis capillaris

Dactylis glomerata

Festuca rubra

Poa pratensis

Phleum pratense

Agropyron repens 

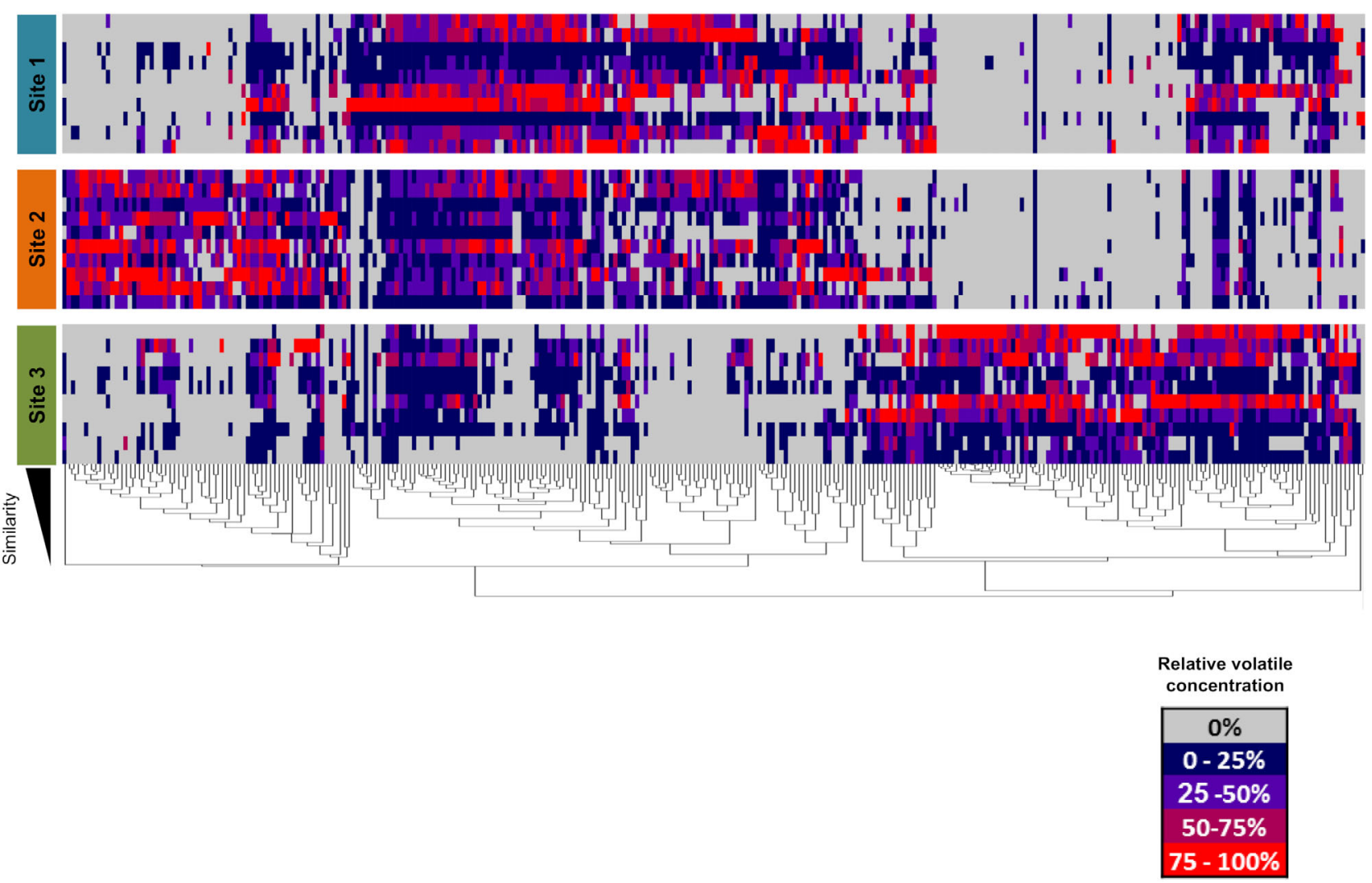

Fig. 2. Heatmap of volatile fingerprints at the three sites. Heatmap illustrating the relative proportion of the 298 TAGs (volatile signals) detected in the soils of each plots for sites 1,2, and 3. The cluster tree, based on correlations, highlights three major clusters: one made of TAGs present almost exclusively in site 2, one made of TAGs common to sites 1 and 2, and one made of TAGs almost only appearing in site 3.

6727 ( \pm 2183$)$ fungal reads and $30360( \pm 2510)$ bacterial reads per sample. Once rarefaction was completed, reads were assigned to 1063 fungal and 3950 bacterial Operational Taxonomic Units (OTUs) during affiliation. These observed OTUs were distributed among plots of all three sites with an average of $267( \pm 41)$ fungal OTUs and 2065 ( \pm 150) bacterial OTUs in site 1, 261 ( \pm 18$)$ fungal and $2002( \pm 177)$ bacterial OTUs in site 2 and $249( \pm 17)$ and 1686 ( \pm 204) bacterial OTUs in site 3. Microbial richness was displayed as observed taxa and diversity was estimated based on Shannon index $\left(H^{\prime}\right)$. Observed richness and estimated diversity among the three sites did not significantly differ for fungi but did so for bacteria (Fig. S3, $p<0.05$ ).

Fungal and bacterial community composition was explored at different taxonomic levels. The Ascomycota phylum dominated fungal community composition in each site (more than $62 \%$ of the total diversity), followed by members of the Basidiomycota and Glomeromycota phyla (Fig. S4). At the class level, the Dothideomycetes (phylum: Ascomycota) were the least abundant in site 3 , which had the highest proportion of Leotiomycetes (Ascomycota). Differences were less apparent for classes within the Basidiomycota and Glomeromycota due to the important variability in relative abundance observed among plots of the same sites (Fig. S4). Seven bacterial phyla represented more than $95 \%$ of the total diversity, with each phylum making up at most $23 \%$ of the overall diversity (Fig. S5). Differences in abundance could also be observed at the class level for bacteria and highlighted once again that site 3 differed the most from the other two sites (Fig. S5).

The standout of site 3 compared with the other sites can similarly be seen at the family level and focusing on the microbial families that represented more than $2 \%$ of the reads (Table 1). These included ten fungal families out of 505 and five bacterial families out of 1768 (refer to Tables S4 and S5 for the data at different taxonomic level). Overall, $60 \%$ of fungal and $86 \%$ bacterial OTUs differed in relative abundance among all sites (Kruskal-Wallis test, $p<0.05$ ). Specifically, site 3 stood out in terms of the Davidiellaceae, Clavariaceae, Geoglossaceae and Glomeraceae fungal families and the Planctomycetaceae, Acidobacteriaceae and Xanthobacteraceae bacterial families (Table 1). The peculiarity of site 3 could also been seen at the OTU level. Indeed, site 3 shared from $5 \%$ to $11 \%$ of microbial OTUs with the other two sites while this number was markedly higher for sites 1 and 2 (19\% to $21 \%$ ). In comparison, the proportion of 
OTUs that were common to all sites were $22 \%$ for fungi and $54 \%$ for bacteria, and all sites had a comparable proportion of site-specific OTUs (2\%-4\% for bacteria, $14 \%-16 \%$ for fungi) (Table S1).

Overall the data illustrate a slightly higher location specificity for fungi compared with bacteria and shows that site 3 differed the most from the other sites in terms of microbial community composition.

Soil volatiles have the strongest associations with plants and microbes

Multiple factor analysis (MFA) was performed with the aim to assess the correlation strength among the soil volatilome and the other factors considered here (plants, microbes, soil properties). The MFA of Fig. 3 highlights that samples from the three sites were distinguishable from each other, and that the MFA model overall explained $39.2 \%$ of total variance (axis 1: $22.1 \%$, axis 2: $17.1 \%$ ). The loadings visible in Fig. 3, indicate that some plants, microbes, nutrients and volatiles/TAGs were driving differences among sites. Three plant species and six TAGs that were the most characteristic of each site have been colour coded in red (panel Vegetation, Fig. 3) and blue (panel Volatiles, Fig. 3). Table S3 furthermore provides the structural identification of those TAGs/volatiles in a handful of cases. Similarly, specific microbial OTUs drove the differences among the sites (refer to Table S4 and S5 for a full list of microbial OTUs, including their occurrence in each site and corresponding statistics). Colour coding microbial OTUs at the phylum level (panels Fungal OTUs and Bacterial OTUs, Fig. 3) did not reveal any obvious site-specific differences in microbial community composition. The shape of the data cloud (triangle shaped for fungi and more donut shaped for bacteria) nevertheless confirms the higher level of site specificity for fungi compared with bacteria already observed previously.

An overall interpretation of the MFA is furthermore achievable through the RV scores which reflects how strongly different loadings (parameters) are associated among each other. RV scores were the highest among volatiles and fungi or plants or bacteria $\left(\mathrm{RV}_{\text {VOLATILES/FUNGI }}=0.77\right.$, $\left.\mathrm{RV}_{\text {VOLATILES/PLANT }}=0.76, \mathrm{RV}_{\text {VOLATILES/BACTERIA }}=0.74\right)$, and were considerably lower between volatiles and nutrients $\left(\mathrm{RV}_{\text {VOLATILES/NUTRIENTS }}=0.52\right)$.

In summary, this highlights a strong association between the soil's volatiles/bacteria, volatiles/fungi and volatiles/ plants, and exemplifies a comparable association strength of those three factors.

\section{Volatiles concentrations correlate to the abundance of specific plants and microbes}

To get a better understanding of specific interactions among volatiles and the three most relevant factors of the MFA (plants, bacteria and fungi), a correlation analysis was applied treating each site independently (i.e., correlation between relative volatiles/TAGs concentrations, plant species and microbial OTUs). The correlation matrices were further filtered by statistics, taking in account only positive or negative significant correlations ( $p<0.05$, t-test) and setting non-significant correlations to zero (Tables S6 (fungi), Table S7 (bacteria), Table S8 (plants)). We first determined which TAGs consistently correlated (positively or negatively) to the same plants or microbial OTUs in at least two sites. This revealed for positive correlations $36 \%$ bacterial OTUs, $26 \%$ fungal OTUs, and $27 \%$ plant species. By contrast,

Table 1. Dominant microbial families with more than $2 \%$ average occurrence in the three sites.

\begin{tabular}{|c|c|c|c|c|c|c|}
\hline Rank & Families (class, phylum) & Site $1(\%)$ & Site $2(\%)$ & Site $3(\%)$ & Average among sites & STE \\
\hline & Fungi & & & & & \\
\hline 1 & Davidiellaceae (Dothideomycetes, Ascomycota) & 17.1 & 12.2 & 4.1 & 11.1 & 3.8 \\
\hline 2 & Clavariaceae (Agaricomycetes, Basidiomycota) & 0.7 & 0.2 & 9.8 & 3.5 & 3.1 \\
\hline 3 & Geoglossaceae (Geoglossomycetes, Ascomycota) & 0.1 & 0.1 & 10.2 & 3.5 & 3.4 \\
\hline 4 & Glomeraceae (Glomeromycetes, Glomeromycota) & 4.3 & 3.7 & 1.2 & 3.1 & 0.9 \\
\hline 5 & Strophariaceae (Agaricomycetes, Basidiomycota) & 5.3 & 1.6 & 1.1 & 2.7 & 1.3 \\
\hline 6 & Sporormiaceae (Dothideomycetes, Ascomycota) & 1.7 & 4.5 & 1.3 & 2.5 & 1.0 \\
\hline 7 & Phaeosphaeriaceae (Dothideomycetes, Ascomycota) & 1.7 & 3.7 & 1.4 & 2.3 & 0.7 \\
\hline 8 & unknown family 421 (Agaricomycetes, Basidiomycota) & 0.2 & 0.1 & 6.5 & 2.3 & 2.1 \\
\hline 9 & Bolbitiaceae (Agaricomycetes, Basidiomycota) & 2.4 & 3.7 & 0.4 & 2.2 & 1.0 \\
\hline \multirow[t]{2}{*}{10} & Pyronemataceae (Pezizomycetes, Ascomycota) & 2.1 & 3.0 & 1.1 & 2.1 & 0.6 \\
\hline & Bacteria & & & & & \\
\hline 1 & DA101 soil group (Spartobacteria, Verrucomicrobia) & 10.7 & 3.1 & 13.9 & 9.2 & 5.3 \\
\hline 2 & Planctomycetaceae (Planctomycetacia, Planctomycetes) & 5.4 & 5.2 & 11.9 & 7.5 & 4.3 \\
\hline 3 & Chitinophagaceae (Sphingobacteriia, Bacteroidetes) & 3.9 & 2.2 & 1.9 & 2.7 & 1.5 \\
\hline 4 & $\begin{array}{l}\text { Acidobacteriaceae (Subgroup 1) (Acidobacteria, } \\
\text { Acidobacteria) }\end{array}$ & 1.0 & 0.3 & 5.6 & 2.3 & 1.3 \\
\hline 5 & Xanthobacteraceae (alpha-proteobacteria, Proteobacteria) & 1.9 & 1.4 & 3.4 & 2.2 & 1.3 \\
\hline
\end{tabular}

STE $=$ standard error 

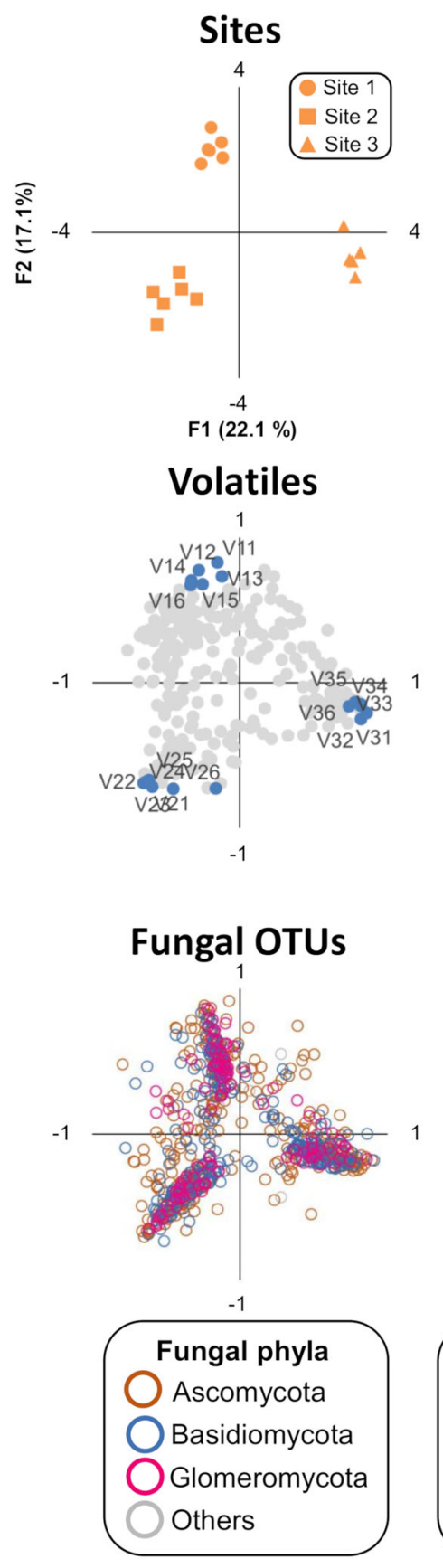

negative correlations with TAGs were observed for only $3 \%$ bacterial OTUs and $1 \%$ fungal OTUs (none were observed with plants).

Considering the predominant numbers of positive correlations among TAGs and microbes or plants, we further questioned which organisms were behind those correlations. Further processing the data of Tables S6, S7 and S8 revealed that single bacterial and fungal OTUs were significantly and positively correlated to a maximum of $15 \%-18 \%$ (average among sites) of all 298 TAGs. This proportion was markedly lower for plants where single species correlated with a
Fig. 3. The MFA was constructed based on vegetation (28 plant species), soil properties (14 parameters), soil volatiles (298 TAGs) and microbial OTUs (1063 fungi and 3950 bacteria). Scores and loadings are shown in six separate plots for the ease of visualization and highlight the relative specificity of some fungal/bacterial OTUs, soil nutrients or TAGs in each site.
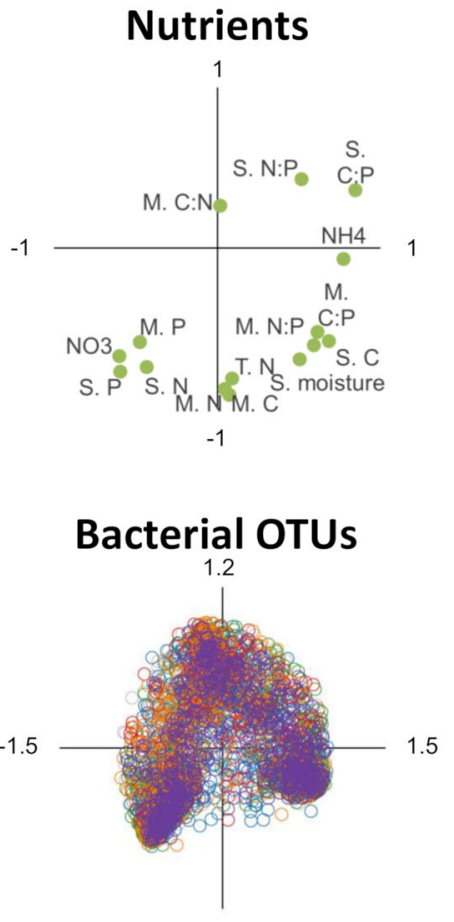

$-1.2$

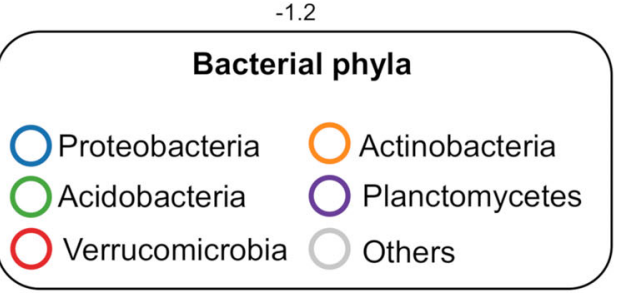




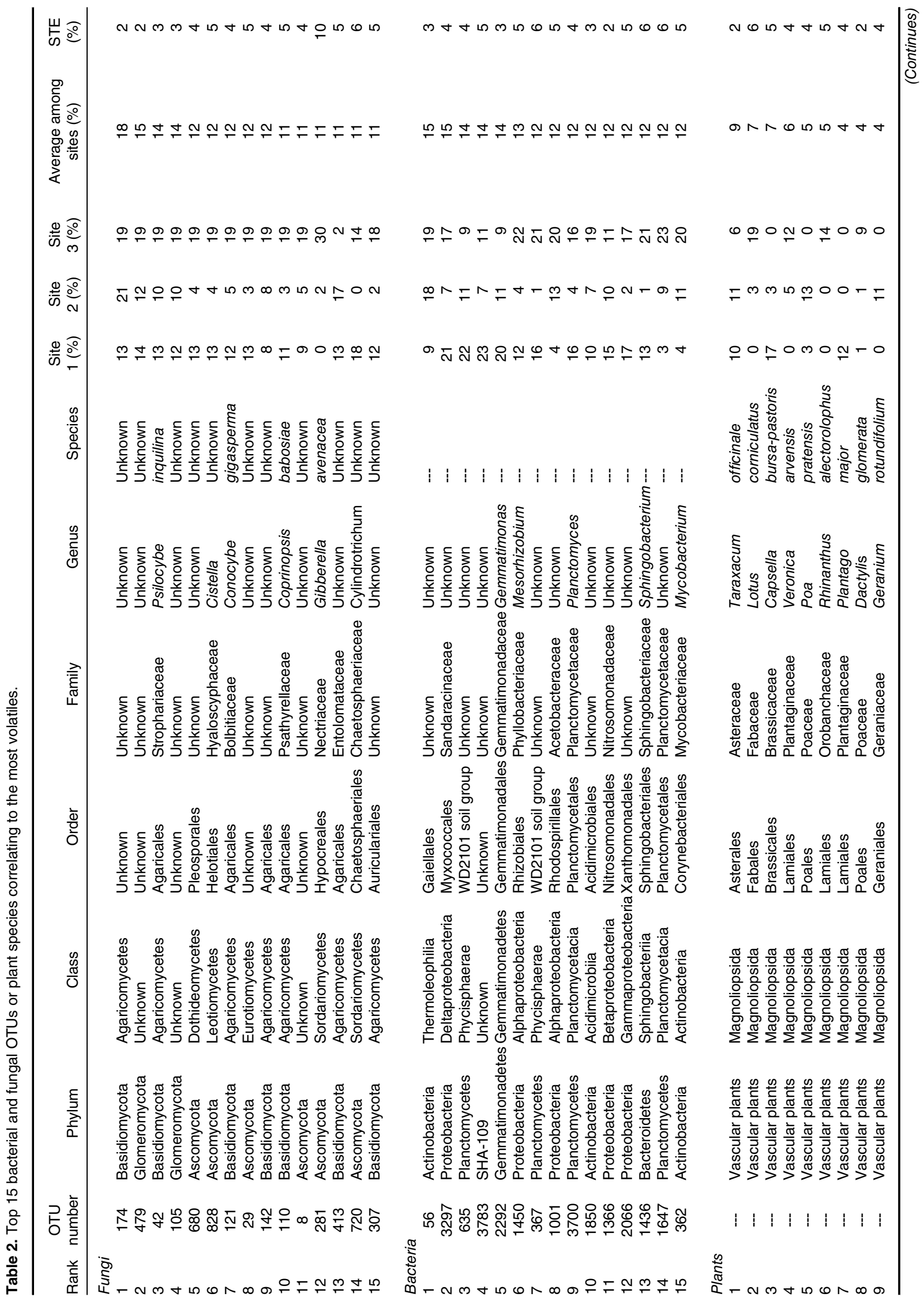


The remaining portion belonged to seven fungal and eight bacterial families, which include for fungi the Hyaloscyphaceae, Psathyrellaceae, Nectriaceae, Entolomataceae, Chaetosphaeriaceae, Strophariaceae and the Bolbitiaceae families. The latter two families belonged to the dominant taxa listed in Table 1. Bacterial families were represented by the Sandaracinaceae, Gemmatimonadaceae, Phyllobacteriaceae, Acetobacteraceae, Nitrosomonadaceae, Sphingobacteriaceae, Mycobacteriaceae and Planctomycetaceae. The latter family was listed as a dominant taxon in to Table 1.

Overall these findings highlight that some microbial OTUs are correlated to a higher proportion of volatiles than single plant species. Our data also reveal the taxonomic identity of the organisms that are correlated to the most TAGs.

\section{Discussion}

The possibility to gain relevant insight in belowground plantmicrobe interactions by profiling soil volatiles in association with plant and microbial community compositions was explored here. Overall, volatile profiles from the soils collected in two sites were highly similar to each other and greatly differed from a third location. Of the four factors considered here, soil nutrients had the lowest association with the soil's volatilome. This is not surprising since soil nutrients have no direct influence on soil volatiles. Yet, they might indirectly influence the physiology of volatile emitters and shape soil's microbiome (Faoro et al., 2010; Wang et al., 2017; Xue et al., 2018), potentially explaining the small effect observed here in the soil volatilome. Indeed the relative proportion of available carbon to nitrogen (C:N) or to phosphorus $(C: P)$, and the ratio of nitrogen to phosphorus $(\mathrm{N}: \mathrm{P})$ are known to impact plant biomass and metabolism (Elser et al., 2010; Güsewell, 2005; Huarancca Reyes et al., 2018; Zheng, 2009). This is further supported by the fact that fertilization treatments of soil have been documented to affect monoand sesquiterpenes emission in plants (Ormeño and Fernandez, 2012). Similarly, the uptake of soil's nutrients by plants was shown to influence the production of volatiles, as illustrated by the finding that phosphorus foliar concentrations negatively correlated to isoprene and monoterpenes emissions (Fernández-Martínez et al., 2018). Additionally, nutrients might similarly affect volatiles synthetized by bacteria (Garbeva et al., 2014).

Microbial community structures and compositions were additional factors considered here for their associations with soil's volatilome. Our data highlight that soil microbes were strongly associated with soil's volatilome. Bacteria and fungi are well known emitters of volatile compounds (Lemfack et al., 2018), and we have speculated earlier based on undescribed (and mostly uncultivable) microbial taxa that soil might contain a huge diversity of undescribed volatiles (Schenkel et al., 2015). This hypothesis is corroborated here 
by the fact that most volatiles of the present study could not be identified. This should, however, be interpreted with caution since part of the difficulty in identifying volatiles might be attributed to low signals in the chromatograms. However, it is also likely that many of the volatiles of the present study have not been described/characterized yet as they originate from a highly complex matrix (soil) that has been little studied (Peñuelas et al., 2014). A similar observation about the need to characterize the structure of unknown bacterial volatile has been done earlier (Kai et al., 2009). Future efforts should thus focus on identifying specific soil volatiles and linking those volatiles to distinct microbes and biosynthesis pathways.

In addition to the strong associations evidenced by the MFA, significant positive correlations were observed between volatile signals and specific plants. Current knowledge of volatile emission by plant roots is scarce (Schenkel et al., 2015) and to the best of our knowledge, there is no published data on the root volatilomes of any of the plant (grass) species listed as relevant in Table 2. By contrast some data exists on the volatilomes of some of the relevant microbial taxa listed in Table 2. For instance, the volatile profile of the plant pathogen Gibberella avenacea, (teleomorph of Fusarium avenaceum) has been investigated during infection of maize ears (Becker et al., 2014). Additionally, the volatile profiles of other Fusarium species have been characterized in numerous other studies (Bitas and Kang, 2015; Lemfack et al., 2018; Schenkel et al., 2018; Wang et al., 2018). Two unidentified OTUs belonging to the Glomeromycota phylum known for its ability to form arbuscular mycorrhizae with plants were also put forward as possible emitter of volatiles (Table 2). Studies on the volatile emission in in vitro cultures of arbuscular mycorrhizal fungi have been hindered by the microscopic size of those organisms and probably by technological challenges in cultivation (Mukhongo et al., 2016). Nevertheless, arbuscular mycorrhizal fungi are known to alter the above-ground volatile emission of the plants they colonize (Schausberger et al., 2012), thus it is conceivable that a similar modulation might occur at the plant root level. Lastly, microbes do not only have the ability to emit volatiles but possibly also to adsorb or even metabolize them as recently suggested for fungi and soil volatiles (Schenkel et al., 2018) or for bacteria and the volatile cumene (Eaton and Nitterauer, 1994; Habe et al., 1996). Yet, the higher proportion of positive correlations compared with negative ones between volatile signals and plants or microbes observed in our data suggests that overall, soil organisms are emitting more volatiles than they consume.

In conclusion, the soil volatilome should be considered as a signature resulting from the net effect of all organisms and processes acting in the soil. Additionally, the scare information on the volatilome of organisms listed as relevant here begs for characterizing their volatile profiles.

The data presented here furthermore highlight a higher level of site-specificity for fungi than for bacteria. Certain dominant fungi have closer associations with plant roots (i.e. forming mycorrhizas) than bacteria, and the higher specificity observed for fungi might thus be driven by the stark differences in plant communities between sites 1 and 2 compared with site 3 . However, our sampling strategy might also have influenced this outcome. Indeed, bacteria might closely associate with plant roots at the level of the rhizosphere, a thin zone of soil directly under the influence of plant roots that is known to contain most microbes relevant for plant health (Berendsen et al., 2012). Considering that our sampling strategy, established to minimize wound-induced root volatiles, included both rhizosphere and bulk soil, our results should be interpreted with a note of caution. Indeed, signals from rhizosphere bacteria might be diluted by signals from bulk soil bacteria. A stricter sampling of rhizosphere microbial communities might thus have revealed more of the plant associated active microbes. However, the detection of some OTUs belonging to the Proteobacteria phylum, and that represented approximately $20 \%$ of the bacterial diversity in our data, validates at least partially our sampling strategy. These microbes are indeed known as common rhizosphere inhabitants and endophytes in several grass species (Duc et al., 2009; Hurek et al., 2002; Iniguez et al., 2004; Sevilla et al., 2001). Additional studies focusing on the bacterial communities in the rhizosphere of single plant species will be needed to pinpoint microbial specificity/ubiquity.

In summary, our findings illustrate some of the challenges in studying the soil's volatilome but also highlight its high complexity. Most of all, soil microbes appear as essential emitters of volatiles and seem to contribute slightly more than plant roots to the complexity of the soil's volatilome. Further studies are nevertheless required to verify whether our observations are global or local and how they vary in space and time.

\section{Experimental procedures}

\section{Site description and experimental design}

Three semi-natural grasslands located in the Jura Mountains (Canton of Vaud, Switzerland) were characterized in terms of plant communities, soil nutrients, soil volatilomes and microbiomes. Details about each site can be seen in the Supporting Information Table S2.

Five rainout shelters were set up at each site. The experiment was conducted during two growing season using plots of $3.6 \mathrm{~m}^{2}$ and data for this study were collected in the second year of the experiment (2016). The current study included two plots per shelter (considering five shelters per site, this is equivalent to 10 plots per site), which were irrigated for 8 weeks with different watering regimes to assess the effect of drought. Specifically, a 'control plot' was watered based on the averaged precipitations of the last 30 years while the 'drought plot' received $30 \%$ less water. Because statistical testing 
revealed that the effect of drought on the soil volatilome was negligible (it significantly influenced the concentrations of only $6 \%$ of volatiles for site $1,3 \%$ for site 2 and $4 \%$ for site $3, p<0.05$, Kruskall-Wallis test), the two plots (drought and the respective control plot) were considered here as equivalent.

Vegetation cover determination, soil sampling (for nutrients, microbiomes, volatilomes) and subsequent plant yield were determined at the end of the 8 weeks period. The specific sampling dates (end of May for site 1, midJune for site 2 and early July for site 3 ) differed for each site as they were chosen to reflect peak biomass (based on data obtained in the previous years). The exact number of replicates (plots) sampled at each site was for vegetation determination and soil's volatilome - 10 plots per site; soil nutrients -6 plots per site and for bacterial and fungal microbiomes -10 plots per site, except for site 3 for which one bacterial microbiome sample was lost resulting in 9 plots.

\section{Determination of vegetation}

Plant community was surveyed using a pin-point method (Daget and Poissonet, 1971) with 80 points per plot, evenly distributed every $20 \mathrm{~cm}$ on four lines of $400 \mathrm{~cm}$ spaced $20 \mathrm{~cm}$ apart. At each point of interception, all plant species in contact with the edge of a $1 \mathrm{~mm}$ dagger (presence/absence) were recorded. Relative species cover was determined by dividing the number of contacts per species in each plot by the total number of contacts (lussig et al., 2015). Above ground biomass (plant yield) was determined after harvesting and expressed as dry matter per plot.

\section{Soil nutrients}

Soil samples were collected for the top 12-15 cm layer by pooling 15 spatially randomly distributed cores per plot. The water content was determined gravimetrically by drying soil subsamples at $105^{\circ} \mathrm{C}$ to a constant weight. Total carbon (C) and nitrogen $(\mathrm{N})$ content in the bulk soil were analysed after ball milling. Soil $\mathrm{C}$ and $\mathrm{N}$ were determined under high-temperature oxidation using an elemental analyser (CE Instruments model NA2500 Nitrogen Carbon Analyser) and expressed as $\mathrm{mg} \cdot \mathrm{kg}^{-1} \mathrm{dry}$ soil. For the determination of microbial biomass carbon $\left(\mathrm{C}_{\text {mic }}\right)$ and nitrogen $\left(\mathrm{N}_{\text {mic }}\right)$, pairs of about $5 \mathrm{~g}$ of fresh soil were weighed for each replicate and one sample from each pair was immediately extracted in $25 \mathrm{ml}$ solution of $0.5 \mathrm{M} \mathrm{K}_{2} \mathrm{SO}_{4}$, whereas the other sample was put in a vacuum desiccator and subjected to chloroform vapours. After 1 day of fumigation, the fumigated soil sample was extracted with the same solution. Total $\mathrm{C}$ and $\mathrm{N}$ concentrations in fumigated and non-fumigated samples were analysed by a TOC/TN analyser (Shimadzu TOC-V). To determine the soil available phosphorus $(P)$ and the microbial phosphorus $\left(P_{\text {mic }}\right), 3 \mathrm{~g}$ of fumigated and nonfumigated fresh soil was extracted with $40 \mathrm{ml}$ of $0.5 \mathrm{M}$ $\mathrm{NaHCO}_{3}$ (Olsen method). Phosphorus concentrations (i.e. orthophosphates) were analysed by colorimetry using a spectrophotometer at $890 \mathrm{~nm}$. Microbial biomass $\mathrm{C}, \mathrm{N}$ and $\mathrm{P}$ were estimated as the differences between the amounts of $\mathrm{C}, \mathrm{N}$ and $\mathrm{P}$ after and before fumigation using an extractability factor of 0.45 for $\mathrm{C}$ (Vance et al., 1987), 0.54 for $N$ (Brookes et al., 1985) and 0.4 for $\mathrm{P}$ (Brookes et al., 1982). Microbial biomass C, $\mathrm{N}$ and $\mathrm{P}$ and soil available $\mathrm{P}$ are expressed as $\mathrm{mg} \cdot \mathrm{kg}^{-1}$ dry soil. Ammonium $\left(\mathrm{N}-\mathrm{NH}_{4}\right)$ and nitrate $\left(\mathrm{N}-\mathrm{NO}_{3}\right)$ concentrations were determined by continuous flow analyses using an automated analyser (SEAL AA3 HR Autoanalyser) after extraction of $5 \mathrm{~g}$ of fresh soil with $30 \mathrm{ml}$ of $1 \mathrm{M} \mathrm{KCl}$, and the results expressed as milligram per kilogram dry soil.

\section{Sampling of soil for volatilome and microbiome analysis}

Soil was sampled from each plot according to the scheme described in the Supporting Information Fig. S6. In short, six soil cores (12-15 cm depth, $3.2 \mathrm{~cm}$ diameter) were taken from each plot. Soil cores contained highly intermingled roots (a few milligram of roots per grams of soil - dry weight each). Separating rhizosphere from bulk soil was not feasible without extensively damaging root systems and thus inducing the release of wound-induced volatiles. Hence, root samples were immediately separated at the sampling site from soil through sieving $(3 \mathrm{~mm}$ sieve). This resulted in a mixture of bulk and rhizosphere soil that was subsequently used to determine soil's volatilome and microbiome as described hereafter. To minimize volatile loss or drift in microbial population following sampling, the soil samples were cooled to $4^{\circ} \mathrm{C}$ until volatile profiling was performed (within $24 \mathrm{~h}$ from collection) and immediately frozen thereafter.

\section{Soil volatile profiling}

A total of $1.00( \pm 0.02) \mathrm{g}$ fresh soil of each sample was transferred to $20 \mathrm{ml}$ solid-phase micro extraction (SPME) vials. Volatile fingerprints were generated by SPME-GC/MS and analysed as described previously (Sherif et al., 2016; Schenkel et al., 2018) with the exception of the threshold of 600 set in the Tagfinder software (version 4.1) used to process chromatograms (Luedemann et al., 2008). This analysis resulted in a matrix of TAGs, signals equivalent to mass fragments within specific time ranges [ $(m / z, R T$ range $)]$, and which were normalized to the total ion current (TIC). To filter noise out of the data, only TAGs present in six plots (out of 10) at a single site were considered. TAGs were further 
filtered by retention time and pairwise correlations were calculated with adjacent TAGs. TAGs with a correlation of more than $70 \%$ with the adjacent TAG and falling in a comparable retention window were assumed to belong to the same compound. The data were subsequently reduced to one representative TAG for each TAG having a comparable RT range, resulting in a matrix of 298 TAGs.

Volatiles comprised TAGs of interest were tentatively identified via NIST Mass Spectral Search Program 2.0 (National Institute of Standards and Technology, Gaithersburg, USA) by comparison of mass spectra and Kovats retention indices (n-alkane). Complete identification was achieved for 2-methylbutan-1-ol and 3-methylbutan-1-ol by injecting authentic standards purchased from Merck (Darmstadt, Germany). Raw chromatograms of a representative soil sample per site and respective alkane series are provided as Supporting Information in the CDF format.

\section{Microbiome sequencing and data preprocessing}

Soil samples (100 g per soil plot) were freeze dried (Christ Alpha 1-4 LD plus, Osterode am Harz, Germany) and subsequently homogenized by mixing/shaking in paper bags. For each sample, the DNA from three subsamples of $250 \pm 10 \mathrm{mg}$ soil was isolated with the NucleoSpin Soil Kit (Macherey-Nagel, Düren, Germany) according to the manufacturer's instruction (using lysis buffer SL2 $+150 \mu \mathrm{l}$ enhancer). Eventually, the three subsamples of isolated microbial DNA were unified into one sample resulting in 30 samples in total (one for each plot).

Amplicon libraries of bacterial soil inhabitants were generated by amplifying the $\mathrm{V} 4$ region of the bacterial $16 \mathrm{~S}$ rDNA with 515F (Apprill et al., 2015) and 806R (Parada et al., 2016) primers. The internal transcribed spacer 2 (ITS2) region of fungal rDNA was used to characterize fungal soil communities using ITS86F (Vancov and Keen, 2009) and ITS4 (White et al., 1990) primers. In both cases, forward and reverse primers carried the 5-CTTTCCCTACACGACGCT CTTCCGATCT-3 and 5-GGAGTTCAGACGTGTGCTCT TCCGATCT-3 tails. Bacterial amplicon size was approximately 291 base pairs (bp) (Caporaso et al., 2011), fungal amplicon size approximately $400 \mathrm{bp}$ (Vancov and Keen, 2009). Oligo nucleotides were obtained from Eurofins Genomics (Ebersberg, Germany). Polymerase chain reaction (PCR) was performed for three replicates of each sample

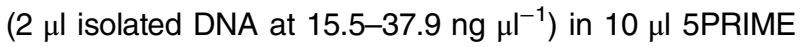
$2.5 \times$ MasterMix including Taq polymerase with $1 \mu \mathrm{l}$ of forward and reverse primers $(10 \mu \mathrm{M})$ each and $11 \mu \mathrm{LNA}$ free water (Carl Roth, France) in a total reaction volume of $25 \mu \mathrm{l}$ per sample. Amplification conditions for bacterial $16 \mathrm{~S}$ oligonucleotides were $94^{\circ} \mathrm{C}$ for $3 \mathrm{~min}, 30$ cycles $94^{\circ} \mathrm{C}$ for $45 \mathrm{~s}$, $50^{\circ} \mathrm{C}$ for $1 \mathrm{~min}$ and $72^{\circ} \mathrm{C}$ for $90 \mathrm{~s}$. Eventually temperature was hold at $72^{\circ} \mathrm{C}$ for $10 \mathrm{~min}$ and storage at $4^{\circ} \mathrm{C}$. Amplification conditions for ITS2 oligonucleotides were $95^{\circ} \mathrm{C}$ for
$2 \mathrm{~min}$, then 30 cycles of $95^{\circ} \mathrm{C}$ for $30 \mathrm{~s}, 55^{\circ} \mathrm{C}$ for $30 \mathrm{~s}, 72^{\circ} \mathrm{C}$ for $1 \mathrm{~min}$ and after the final cycle $72^{\circ} \mathrm{C}$ for $10 \mathrm{~min}$, followed by $10^{\circ} \mathrm{C}$ for storage. PCR products without addition of microbial DNA (negative control), mock communities of known fungal or bacterial compositions and unmerged subsamples of two randomly picked samples were added as quality controls. Samples of $50 \mu \mathrm{l}$ (30 ng DNA per $\mu \mathrm{l})$ were sent for tagging and MiSeq Illumina Next Generation Sequencing (GeT PlaGe INRA sequencing platform, Toulouse, France). The raw data were deposited in the NCBI Sequence Read Archive website (http://www.ncbi.nlm.nih.gov/sra) under the SRA study accession number SUB5130080.

Resulting bacterial sequences were further processed with Find Rapidly OTU with Galaxy Solution (FROGS) (Escudié et al., 2017) based on Galaxy metagenomic analysis platform (Afgan et al., 2016). Sequences were demultiplexed, dereplicated, sequence quality was checked, oligonucleotides, linker, pads and barcodes were removed from sequences and sequences were filtered on additional criteria. Sequences were removed from data set, if nonbarcoded, if sequences exhibited ambiguous bases or did not match expectations in amplicon size. Remaining sequences were clustered into operational taxonomic units (OTUs) based on iterative Swarm algorithm, and then chimera and singletons (OTUs containing only one sequence) were removed. Bacterial double affiliation was performed blasting OTUs against SILVA database (Quast et al., 2012) and ribosomal database project (RDP) classifier (Wang et al., 2007). OTUs with affiliation $<100 \%$ at phylum level (indicated by a RDP bootstrap value $<1$ ) were removed from data set. OTUs at lower taxonomic ranks than the phylum level were considered as 'unidentified' when RDP bootstrap value was $<0.70$. OTUs with high abundances in negative controls were excluded from further analysis, sequencing and affiliation quality was evaluated based on the results obtained for the bacterial mock community.

Fungal sequences were processed as following. After demultiplexing and quality check (quality score $=30$, minimal size $=200 \mathrm{bp}$ ), bioinformatics analyses were performed using standard procedures as described in the study by Pérez-Izquierdo et al. (2017).

For both fungal and bacterial data, per-sample rarefaction curves were calculated to assess sampling completeness, using function rarecurve() in package Vegan v3.5-1 (Oksanen et al., 2015) in R (version 3.4.3) (R Core Team, 2017). Based on these, subsequent analyses of diversity and community structure were performed on data sets where samples had been rarefied with the Phyloseq (McMurdie and Holmes 2013) package to achieve equal read numbers according to the minimum number of total reads in any sample (25 143 bacteria, 4127 fungi). Microbial alpha diversity was estimated with the PhyloSeq package, as well. Normal distribution of richness (observed taxa) and diversity (Shannon's H') was tested (Shapiro-Wilk normality 
test) for fungi and bacteria individually. Depending on the outcome, richness and diversity of sites 1-3 were compared by ANOVA (normal distribution) or Kruskal-Wallis test (not normal distribution).

\section{Statistical analysis}

Tests for statistical significance were computed in Past 3.04 (Hammer et al., 2001) or R [version 3.4.3 (R Core Team, 2017)] and packages within. The exact tests performed are specified in the figure's legends or main text.

Multiple factor analysis. MFAs was performed considering all three sites using XLStat (version 2015 1.01; Addinsoft SARI, Paris, France). MFA requires data matrices (plants, microbes, soil nutrients and volatiles) of the same size (number of scores). Because soil nutrient content had been determined from only six plots per site, only data from the corresponding six plots (five for site 3 due to a missing sample) were considered to generate the relevant matrices for plants, microbes and volatiles. Specifically, the following matrices were used (i) the normalized matrix generated under "Soil volatile profiling" and containing 298 TAGs (volatiles); (ii) for plants, the relative abundance of 38 species were expressed in percentage for each plot; and (iii) for microbes, the relative abundance of 3950 bacterial and 1063 fungal OTUs were expressed as the number of reads detected in each plot. Nutrients and nutrient ratios were expressed as illustrated in the Supporting Information Fig. S1. RV coefficients computed by the MFA range from zero to one and the higher the score, the stronger the association between two data matrices.

Correlation analysis. Correlations among volatiles, plant species and microbial OTU were calculated in Past 3.04 (Hammer et al., 2001) considering each sites separately. Values (Person's R) with non-significant correlations ( $p>0.05$, t- test) were replaced by zero, resulting in three separate correlation matrices that contained only significant positive and negative correlations [Supporting Information Tables S6 (fungi), Table S7 (bacteria), Table S8 (plants)].

\section{Acknowledgements}

The authors are thankful to Luc Stévenin for his assistance in collecting soil samples. Research funding was provided for DS and RS through the LOEWE research program of the government of Hesse, Germany, in the framework of the Integrative Fungal Research Cluster (IPF) and for AV, MM, PM and AB through the Swiss SNF grant CR3113_156282/1. The Laboratory of Excellence Advanced Research on the Biology of Tree and Forest Ecosystems (ARBRE; ANR-11-LABX 0002 01 ) provided funding to $A D$ for amplicon sequencing. We are grateful to the INRA MIGALE bioinformatics platform (http:// migale.jouy.inra.fr) for providing computational resources.

\section{Authors contributions}

$M M$ and $A B$ conceived the field trials in Switzerland. AV, $\mathrm{MM}$ and $\mathrm{DS}$ collected soil samples. AV and MM determined vegetation composition and yield. $P M$ and $A B$ analysed the nutrient content of soil samples. $D S$ and $A D$ characterized the soil's microbiome. DS and RS analysed the soil's volatilome. DS, JN, PM and RS synthesized the data and performed data analysis and statistics. DS, RS and $\mathrm{JN}$ wrote the manuscript with input from all other coauthors.

\section{Conflict of interest}

The authors declare no conflict of interest of any sort.

\section{References}

Afgan, E., Baker, D., van den Beek, M., Blankenberg, D., Bouvier, D., Čech, M., et al. (2016) The galaxy platform for accessible, reproducible and collaborative biomedical analyses: 2016 update. Nucleic Acids Res 44: W3-W10. https://doi.org/10.1093/nar/gkw343 W1.

Almario, J., Jeena, G., Wunder, J., Langen, G., Zuccaro, A., Coupland, G., and Bucher, M. (2017) Root-associated fungal microbiota of nonmycorrhizal Arabis alpina and its contribution to plant phosphorus nutrition. Proc Natl Acad Sci 114: E9403-E9412. https://doi.org/10.1073/pnas.1710455114.

Apprill, A., McNally, S., Parsons, R., and Weber, L. (2015) Minor revision to V4 region SSU rRNA 806R gene primer greatly increases detection of SAR11 bacterioplankton. Aquat Microb Ecol 75: 129-137. https://doi.org/10.3354/ame01753.

Bahram, M., Põlme, S., Kõljalg, U., and Tedersoo, L. (2011) A single European aspen (Populus tremula) tree individual may potentially harbour dozens of Cenococcum geophilum ITS genotypes and hundreds of species of ectomycorrhizal fungi: Ectomycorrhizal fungi of a single aspen tree. FEMS Microbiol Ecol 75: 313-320. https://doi.org/10.1111/j.15746941.2010.01000.x.

Becker, E.-M., Herrfurth, C., Irmisch, S., Köllner, T.G., Feussner, I., Karlovsky, P., and Splivallo, R. (2014) Infection of corn ears by Fusarium spp. induces the emission of volatile Sesquiterpenes. J Agric Food Chem 62: 5226-5236. https://doi.org/10.1021/f500560f.

Berendsen, R.L., Pieterse, C.M.J., and Bakker, P.A.H.M. (2012) The rhizosphere microbiome and plant health. Trends Plant Sci 17: 478-486. https://doi.org/10.1016/j. tplants.2012.04.001.

Bitas, V., McCartney, N., Li, N., Demers, J., Kim, J.-E., Kim, H.-S., et al. (2015) Fusarium oxysporum volatiles enhance plant growth via affecting auxin transport and signaling. Front Microbiol 6: 1248.

Bonfante, P., and Genre, A. (2010) Mechanisms underlying beneficial plant-fungus interactions in mycorrhizal symbiosis. Nat Commun 1: 1-11. https://doi.org/10.1038/ncomms1046.

Brookes, P.C., Landman, A., Pruden, G., and Jenkinson, D. S. (1985) Chloroform fumigation and the release of soil nitrogen: a rapid direct extraction method to measure 
microbial biomass nitrogen in soil. Soil Biol Biochem 17: 837-842. https://doi.org/10.1016/0038-0717(85)90144-0.

Brookes, P.C., Powlson, D.S., and Jenkinson, D.S. (1982) Measurement of microbial biomass phosphorus in soil. Soil Biol Biochem 14: 319-329. https://doi.org/10.1016/ 0038-0717(82)90001-3.

Bulgarelli, D., Schlaeppi, K., Spaepen, S., van Themaat, E. V.L., and Schulze-Lefert, P. (2013) Structure and functions of the bacterial microbiota of plants. Annu Rev Plant Biol 64: 807-838. https://doi.org/10.1146/annurev-arplant050312-120106.

Caporaso, J.G., Lauber, C.L., Walters, W.A., Berg-Lyons, D., Lozupone, C.A., Turnbaugh, P.J., et al. (2011) Global patterns of 16S rRNA diversity at a depth of millions of sequences per sample. Proc Natl Acad Sci 108: 4516-4522. https://doi.org/10.1073/pnas.1000080107.

Christenhusz, M.J.M., and Byng, J.W. (2016) The number of known plants species in the world and its annual increase. Phytotaxa 261: 201. https://doi.org/10.11646/phytotaxa.261.3.1.

Daget, P., and Poissonet, J. (1971) Une méthode d'analyse phytologique des prairies: critères d'application. Ann Agron 22: 5-41.

Deveau, A. (2016) How does the tree root microbiome assemble? Influence of ectomycorrhizal species on Pinus sylvestris root bacterial communities. Environ Microbiol 18: 1303-1305. https://doi.org/10.1111/1462-2920.13214.

Duc, L., Noll, M., Meier, B.E., Bürgmann, H., and Zeyer, J. (2009) High diversity of diazotrophs in the forefield of a receding alpine glacier. Microb Ecol 57: 179-190. https:// doi.org/10.1007/s00248-008-9408-5.

Eaton, R.W., and Nitterauer, J.D. (1994) Biotransformation of benzothiophene by isopropylbenzene-degrading bacteria. J Bacteriol 176: 3992-4002.

Edwards, J., Johnson, C., Santos-Medellín, C., Lurie, E., Podishetty, N.K., Bhatnagar, S., et al. (2015) Structure, variation, and assembly of the root-associated microbiomes of rice. Proc Natl Acad Sci 112: E911-E920. https://doi.org/ 10.1073/pnas.1414592112.

El Komy, M.H., Saleh, A.A., Eranthodi, A., and Molan, Y.Y. (2015) Characterization of novel Trichoderma asperellum isolates to select effective biocontrol agents against tomato Fusarium wilt. Plant Pathol J 31: 50-60. https://doi. org/10.5423/PPJ.OA.09.2014.0087.

Elser, J.J., Fagan, W.F., Kerkhoff, A.J., Swenson, N.G., and Enquist, B.J. (2010) Biological stoichiometry of plant production: metabolism, scaling and ecological response to global change: Tansley review. New Phytol 186: 593-608. https://doi.org/10.1111/j.1469-8137.2010.03214.x.

Escudié, F., Auer, L., Bernard, M., Mariadassou, M., Cauquil, L., Vidal, K., et al. (2017) FROGS: find, rapidly, OTUs with galaxy solution. Bioinformatics 34: 1287-1294. https://doi.org/10.1093/bioinformatics/btx791.

Faoro, H., Alves, A.C., Souza, E.M., Rigo, L.U., Cruz, L.M., Al-Janabi, S.M., et al. (2010) Influence of soil characteristics on the diversity of bacteria in the southern Brazilian Atlantic Forest. Appl Environ Microbiol 76: 4744-4749. https://doi.org/10.1128/AEM.03025-09.

Farzaneh, M., Vierheilig, H., Lössl, A., and Kaul, H.P. (2011) Arbuscular mycorrhiza enhances nutrient uptake in chickpea. Plant Soil Environ 57: 465-470. https://doi.org/10. 17221/133/2011-PSE No. 10.
Fernández-Martínez, M., Llusià, J., Filella, I., Niinemets, Ü., Arneth, A., Wright, I.J., et al. (2018) Nutrient-rich plants emit a less intense blend of volatile isoprenoids. New Phytol 220: 773-784. https://doi.org/10.1111/nph.14889.

Frąc, M., Hannula, S.E., Bełka, M., and Jędryczka, M. (2018) Fungal biodiversity and their role in soil health. Front Microbiol 9: 707. https://doi.org/10.3389/fmicb.2018. 00707.

Garbeva, P., Hordijk, C., Gerards, S., and de Boer, W. (2014) Volatiles produced by the mycophagous soil bacterium Collimonas. FEMS Microbiol Ecol 87: 639-649. https://doi.org/ 10.1111/1574-6941.12252.

Gómez Expósito, R., de Bruijn, I., Postma, J., and Raaijmakers, J. M. (2017) Current insights into the role of rhizosphere bacteria in disease suppressive soils. Front Microbiol 8: 2529. https:// doi.org/10.3389/fmicb.2017.02529.

Güsewell, S. (2005) High nitrogen: phosphorus ratios reduce nutrient retention and second-year growth of wetland sedges. New Phytol 166: 537-550. https://doi.org/10. 1111/j.1469-8137.2005.01320.x.

Habe, H., Kasuga, K., Nojiri, H., Yamane, H., and Omori, T. (1996) Analysis of cumene (isopropylbenzene) degradation genes from Pseudomonas fluorescens IP01. Appl Environ Microbiol 62: 4471-4477.

Hacquard, S., Garrido-Oter, R., González, A., Spaepen, S., Ackermann, G., Lebeis, S., et al. (2015) Microbiota and host nutrition across plant and animal kingdoms. Cell Host Microbe 17: 603-616.

Hacquard, S., Spaepen, S., Garrido-Oter, R., and SchulzeLefert, P. (2017) Interplay between innate immunity and the plant microbiota. Annu Rev Phytopathol 55: 565-589.

Hammer, Ø., Harper, D.A.T., and Ryan, P.D. (2001) Past: paleontological statistics software package for education and data analysis. Palaeontol Electron 4: 9. https://palaeoelectronica.org/2001_1/past/past.pdf

Huarancca Reyes, T., Scartazza, A., Pompeiano, A., Ciurli, A., Lu, Y., Guglielminetti, L., and Yamaguchi, J. (2018) Nitrate Reductase modulation in response to changes in $\mathrm{C} / \mathrm{N}$ balance and nitrogen source in Arabidopsis. Plant Cell Physiol 59: 1248-1254. https://doi.org/10.1093/pcp/pcy065.

Hurek, T., Handley, L.L., Reinhold-Hurek, B., and Piché, Y. (2002) Azoarcus grass endophytes contribute fixed nitrogen to the plant in an unculturable state. Mol Plant Microbe Interact 15: 233-242. https://doi.org/10.1094/MPMl.2002.15.3.233.

Iniguez, A.L., Dong, Y., and Triplett, E.W. (2004) Nitrogen fixation in wheat provided by Klebsiella pneumoniae 342. Mol Plant Microbe Interact 17: 1078-1085. https://doi.org/ 10.1094/MPMI.2004.17.10.1078.

lussig, G., Lonati, M., Probo, M., Hodge, S., and Lombardi, G. (2015) Plant species selection by goats foraging on montane seminatural grasslands and Grazable forestlands in the Italian Alps. Ital J Anim Sci 14: 3907. https://doi.org/10.4081/ijas.2015.3907.

Kai, M., Haustein, M., Molina, F., Petri, A., Scholz, B., and Piechulla, B. (2009) Bacterial volatiles and their action potential. Appl Microbiol Biotechnol 81: 1001-1012. https://doi.org/10.1007/s00253-008-1760-3.

Kia, S.H., Glynou, K., Nau, T., Thines, M., Piepenbring, M., and Maciá-Vicente, J.G. (2017) Influence of phylogenetic conservatism and trait convergence on the interactions between fungal root endophytes and plants. ISME J 11: 777-790. https://doi.org/10.1038/ismej.2016.140. 
Kielak, A.M., Barreto, C.C., Kowalchuk, G.A., van Veen, J.A., and Kuramae, E.E. (2016) The ecology of Acidobacteria: moving beyond genes and genomes. Front Microbiol 7: 744. https://doi.org/10.3389/fmicb.2016.00744.

Lemfack, M.C., Gohlke, B.-O., Toguem, S.M.T., Preissner, S., Piechulla, B., and Preissner, R. (2018) mVOC 2.0: a database of microbial volatiles. Nucleic Acids Res 46: D1261-D1265. https://doi.org/10.1093/nar/gkx1016.

Luedemann, A., Strassburg, K., Erban, A., and Kopka, J. (2008) TagFinder for the quantitative analysis of gas chromatography--mass spectrometry (GC-MS)-based metabolite profiling experiments. Bioinformatics 24: 732-737. https:// doi.org/10.1093/bioinformatics/btn023.

Mansfield, J., Genin, S., Magori, S., Citovsky, V., Sriariyanum, M., Ronald, P., et al. (2012) Top 10 plant pathogenic bacteria in molecular plant pathology: top 10 plant pathogenic bacteria. Mol Plant Pathol 13: 614-629. https://doi.org/10.1111/j.13643703.2012.00804.x.

Mariotte, P., Canarini, A., and Dijkstra, F.A. (2017) Stoichiometric N:P flexibility and mycorrhizal symbiosis favour plant resistance against drought. $J$ Ecol 105: 958-967. https://doi.org/10.1111/1365-2745.12731.

Mariotte, P., Vandenberghe, C., Kardol, P., Hagedorn, F., and Buttler, A. (2013) Subordinate plant species enhance community resistance against drought in semi-natural grasslands. J Ecol 101: 763-773. https://doi.org/10.1111/1365-2745.12064.

Martin, F., and Kamoun, S. (eds). (2011) Effectors in PlantMicrobe Interactions: Martin/Effectors in Plant-Microbe Interactions. Oxford, UK: Wiley-Blackwell. https://doi.org/ 10.1002/9781119949138.

Marupakula, S., Mahmood, S., and Finlay, R.D. (2016) Analysis of single root tip microbiomes suggests that distinctive bacterial communities are selected by Pinus sylvestris roots colonized by different ectomycorrhizal fungi: ectomycorrhiza-associated bacterial communities. Environ Microbiol 18: 1470-1483. https://doi.org/10.1111/1462-2920.13102.

Massalha, H., Korenblum, E., Tholl, D., and Aharoni, A. (2017) Small molecules below-ground: the role of specialized metabolites in the rhizosphere. Plant $J$ 90: 788-807. https://doi.org/10.1111/tpj.13543.

McCormick, S.P., Stanley, A.M., Stover, N.A., and Alexander, N. J. (2011) Trichothecenes: from simple to complex Mycotoxins. Toxins 3: 802-814. https://doi.org/10.3390/toxins3070802.

McMurdie, P.J., and Holmes, S. (2013) phyloseq: An R Package for reproducible interactive analysis and graphics of microbiome census data. PLOS ONE 8: e61217.

Mendes, L.W., Kuramae, E.E., Navarrete, A.A., van Veen, J.A., and Tsai, S.M. (2014) Taxonomical and functional microbial community selection in soybean rhizosphere. ISME J 8: 1577-1587. https://doi.org/10.1038/ismej.2014.17.

Mendes, R., Garbeva, P., and Raaijmakers, J.M. (2013) The rhizosphere microbiome: significance of plant beneficial, plant pathogenic, and human pathogenic microorganisms. FEMS Microbiol Rev 37: 634-663.

Mukhongo, R.W., Tumuhairwe, J.B., Ebanyat, P., AbdelgGadi, A. H., Thuita, M., and Masso, C. (2016) Production and use of Arbuscular Mycorrhizal fungi inoculum in sub-Saharan Africa: challenges and ways of improving. Int J Soil Sci 11: 108-122. https://doi.org/10.3923/ijss.2016.108.122.

Naznin, H.A., Kimura, M., Miyazawa, M., and Hyakumachi, M. (2013) Analysis of volatile organic compounds emitted by plant growth-promoting fungus Phoma sp. GS8-3 for growth promotion effects on tobacco. Microbes Environ 28: 42-49. https:// doi.org/10.1264/jsme2.ME12085.

Nissinen, R.M., Männistö, M.K., and van Elsas, J.D. (2012) Endophytic bacterial communities in three arctic plants from low arctic fell tundra are cold-adapted and host-plant specific. FEMS Microbiol Ecol 82: 510-522. https://doi. org/10.1111/j.1574-6941.2012.01464.x.

Ofek-Lalzar, M., Sela, N., Goldman-Voronov, M., Green, S.J., Hadar, Y., and Minz, D. (2014) Niche and host-associated functional signatures of the root surface microbiome. Nat Commun 5: 4950. https://doi.org/10.1038/ncomms5950.

Oksanen, J., Blanchet, F.G., Kindt. R., Legendre. P., Minchin. P. R., O'Hara. R.B, et al. (2015). Vegan: Community Ecology Package. $R$ package vegan, vers. 2.2-1. https://cran.rproject.org/web/packages/vegan/index.html

Ormeño, E., and Fernandez, C. (2012) Effect of soil nutrient on production and diversity of volatile terpenoids from plants. Curr Bioact Compd 8: 71-79. https://doi.org/10. 2174/157340712799828188.

Parada, A.E., Needham, D.M., and Fuhrman, J.A. (2016) Every base matters: assessing small subunit rRNA primers for marine microbiomes with mock communities, time series and global field samples: primers for marine microbiome studies. Environ Microbiol 18: 1403-1414. https://doi.org/10.1111/ 1462-2920.13023.

Parry, D.W., Jenkinson, P., and McLEOD, L. (1995) Fusarium ear blight (scab) in small grain cereals? A review. Plant Pathol 44: 207-238. https://doi.org/10.1111/j.13653059.1995.tb02773.x.

Peñuelas, J., Asensio, D., Tholl, D., Wenke, K., Rosenkranz, M., Piechulla, B., et al. (2014) Biogenic volatile emissions from the soil: biogenic volatile emissions from the soil. Plant Cell Environ 37: 1866-1891. https://doi.org/10.1111/pce.12340.

Pérez-Izquierdo, L., Zabal-Aguirre, M., Flores-Rentería, D., González-Martínez, S.C., Buée, M., and Rincón, A. (2017) Functional outcomes of fungal community shifts driven by tree genotype and spatial-temporal factors in Mediterranean pine forests: outcomes of fungal shifts in Mediterranean forests. Environ Microbiol 19: 1639-1652. https:// doi.org/10.1111/1462-2920.13690.

Persello-Cartieaux, F., Nussaume, L., and Robaglia, C. (2003) Tales from the underground: molecular plant-rhizobacteria interactions. Plant Cell Environ 26: 189-199. https://doi.org/ 10.1046/j.1365-3040.2003.00956.x.

Quast, C., Pruesse, E., Yilmaz, P., Gerken, J., Schweer, T., Yarza, P., et al. (2012) The SILVA ribosomal RNA gene database project: improved data processing and web-based tools. Nucleic Acids Res 41: D590-D596. https://doi.org/10.1093/nar/ gks1219.

R Core Team. (2017) R: A Language and Environment for Statistical Computing. Vienna, Austria: R Foundation for Statistical Computing.

Rasmann, S., Köllner, T.G., Degenhardt, J., Hiltpold, I., Toepfer, S., Kuhlmann, U., et al. (2005) Recruitment of entomopathogenic nematodes by insect-damaged maize roots. Nature 434: 732-737. https://doi.org/10.1038/nature03451.

Rodriguez, R.J., White Jr, J.F., Arnold, A.E., and Redman, R.S. (2009) Fungal endophytes: diversity and functional roles: Tansley review. New Phytol 182: 314-330. https://doi.org/10. 1111/j.1469-8137.2009.02773.x. 
Ryu, C.-M., Farag, M.A., Hu, C.-H., Reddy, M.S., Wei, H.-X., Pare, P.W., and Kloepper, J.W. (2003) Bacterial volatiles promote growth in Arabidopsis. Proc Natl Acad Sci 100: 4927-4932. https://doi.org/10.1073/pnas.0730845100.

Saechow, S., Thammasittirong, A., Kittakoop, P., Prachya, S., and Thammasittirong, S.N.-R. (2018) Antagonistic activity against dirty panicle rice fungal pathogens and plant growth promoting activity of Bacillus amyloliquefaciens BAS23. J Microbiol Biotechnol 28:1527-1535. doi:10.4014.jmb/1804.04025.

Santhanam, R., Luu, V.T., Weinhold, A., Goldberg, J., Oh, Y., and Baldwin, I.T. (2015) Native root-associated bacteria rescue a plant from a sudden-wilt disease that emerged during continuous cropping. Proc Natl Acad Sci 112: E5013-E5020. https://doi.org/10.1073/pnas.1505765112.

Schausberger, P., Peneder, S., Jürschik, S., and Hoffmann, D. (2012) Mycorrhiza changes plant volatiles to attract spider mite enemies: adaptive indirect below- and above-ground interaction. Funct Ecol 26: 441-449. https://doi.org/10.1111/ j.1365-2435.2011.01947.x.

Schenkel, D., Lemfack, M.C., Piechulla, B., and Splivallo, R. (2015) A meta-analysis approach for assessing the diversity and specificity of belowground root and microbial volatiles. Front Plant Sci 6: 707. https://doi.org/10.3389/fpls.2015.00707.

Schenkel, D., Maciá-Vicente, J.G., Bissell, A., and Splivallo, R. (2018) Fungi indirectly affect plant root architecture by modulating soil volatile organic compounds. Front Microbiol 9: 1847. https://doi.org/10.3389/fmicb.2018.01847.

Schlaeppi, K., Dombrowski, N., Oter, R.G., Ver Loren van Themaat, E., and Schulze-Lefert, P. (2014) Quantitative divergence of the bacterial root microbiota in Arabidopsis thaliana relatives. Proc Natl Acad Sci 111: 585-592. https://doi.org/10.1073/pnas.1321597111.

Schulz-Bohm, K., Gerards, S., Hundscheid, M., Melenhorst, J., de Boer, W., and Garbeva, P. (2018) Calling from distance: attraction of soil bacteria by plant root volatiles. ISME J 12: 1252-1262. https://doi.org/10.1038/s41396-017-0035-3.

Sevilla, M., Burris, R.H., Gunapala, N., and Kennedy, C. (2001) Comparison of benefit to sugarcane plant growth and ${ }^{15} \mathrm{~N}_{2}$ incorporation following inoculation of sterile plants with Acetobacter diazotrophicus wild-type and $\mathrm{Nif}^{-}$mutant strains. Mol Plant Microbe Interact 14: 358-366. https://doi. org/10.1094/MPMI.2001.14.3.358.

Sharifi, R., and Ryu, C.-M. (2018) Sniffing bacterial volatile compounds for healthier plants. Curr Opin Plant Biol 44: 88-97. https://doi.org/10.1016/j.pbi.2018.03.004.

Sherif, M., Becker, E.-M., Herrfurth, C., Feussner, I., Karlovsky, P., and Splivallo, R. (2016) Volatiles emitted from maize ears simultaneously infected with two Fusarium species mirror the most competitive fungal pathogen. Front Plant Sci 7: 1460. https://doi.org/10.3389/fpls.2016.01460.

Smith, S.E., and Read, D.J. (2008) Mycorrhizal Symbiosis. 3rd ed. London: Academic Press. https://doi.org/10.1016/ B978-012370526-6.50002-7.

Turner, T.R., James, E.K., and Poole, P.S. (2013) The plant microbiome. Genome Biol 14: 209. https://doi.org/10. 1186/gb-2013-14-6-209.

van Dam, N.M., and Bouwmeester, H.J. (2016) Metabolomics in the rhizosphere: tapping into belowground chemical communication. Trends Plant Sci 21: 256-265. https://doi.org/ 10.1016/j.tplants.2016.01.008.
Vance, E.D., Brookes, P.C., and Jenkinson, D.S. (1987) An extraction method for measuring soil microbial biomass $C$. Soil Biol Biochem 19: 703-707. https://doi.org/10.1016/ 0038-0717(87)90052-6.

Vancov, T., and Keen, B. (2009) Amplification of soil fungal community DNA using the ITS86F and ITS4 primers. FEMS Microbiol Lett 296: 91-96. https://doi.org/10.1111/j. 1574-6968.2009.01621.x.

Vandenkoornhuyse, P., Quaiser, A., Duhamel, M., Le Van, A., and Dufresne, A. (2015) The importance of the microbiome of the plant holobiont. New Phytol 206: 1196-1206. https:// doi.org/10.1111/nph.13312.

Wang, A., Haapalainen, M., Latvala, S., Edelenbos, M., and Johansen, A. (2018) Discriminant analysis of volatile organic compounds of Fusarium oxysporum f. Sp. cepae and Fusarium proliferatum isolates from onions as indicators of fungal growth. Fungal Biol 122: 1013-1022. https://doi.org/10. 1016/j.funbio.2018.07.005.

Wang, Q., Garrity, G.M., Tiedje, J.M., and Cole, J.R. (2007) Naive Bayesian classifier for rapid assignment of rRNA sequences into the new bacterial taxonomy. Appl Environ Microbiol 73: 5261-5267. https://doi.org/10.1128/AEM.00062-07.

Wang, R., Zhang, H., Sun, L., Qi, G., Chen, S., and Zhao, X. (2017) Microbial community composition is related to soil biological and chemical properties and bacterial wilt outbreak. Sci Rep 7: 343. https://doi.org/10.1038/s41598017-00472-6.

Wenke, K., Kai, M., and Piechulla, B. (2010) Belowground volatiles facilitate interactions between plant roots and soil organisms. Planta 231: 499-506. https://doi.org/10.1007/ s00425-009-1076-2.

White, T.J., Bruns, T.D., Lee, S.B., and Taylor, J.W. (1990) Amplification and direct sequencing of fungal ribosomal RNA genes for phylogenetics. In PCR Protocols: A Guide to Methods and Applications. Innis, M.A., Gelfand, D.H., Sninsky, J.J., White, T.J., (eds.). New York, NY: Academic Press, Inc., pp. 315-322.

Xue, P.-P., Carrillo, Y., Pino, V., Minasny, B., and McBratney, A. B. (2018) Soil properties drive microbial community structure in a large scale transect in south eastern Australia. Sci Rep 8: 11725. https://doi.org/10.1038/s41598-018-30005-8.

Zgadzaj, R., Garrido-Oter, R., Jensen, D.B., Koprivova, A., Schulze-Lefert, P., and Radutoiu, S. (2016) Root nodule symbiosis in Lotus japonicus drives the establishment of distinctive rhizosphere, root, and nodule bacterial communities. Proc Natl Acad Sci 113: E7996-E8005. https://doi. org/10.1073/pnas.1616564113.

Zheng, Z.-L. (2009) Carbon and nitrogen nutrient balance signaling in plants. Plant Signal Behav 4: 584-591.

\section{Supporting Information}

Additional Supporting Information may be found in the online version of this article at the publisher's web-site:

Figure S1. Supporting Information Figs S1- S6

Table S1. Supporting Information Tables S1 - S8

Appendix S1. Supplemental Chromatograms (three soil samples and one alkane series) 